\title{
Article
}

\section{Do City Honors Increase Tourism Economic Growth? A Quasi-Natural Experimental Research Study Based on "Civilized City" Selection in China}

\author{
Qiao Chen and Yan Mao*
}

check for updates

Citation: Chen, Q.; Mao, Y. Do City Honors Increase Tourism Economic Growth? A Quasi-Natural

Experimental Research Study Based on "Civilized City" Selection in China. Sustainability 2021, 13, 12545. https://doi.org/10.3390/su132212545

Academic Editor: Andrea Pérez

Received: 20 October 2021

Accepted: 8 November 2021

Published: 13 November 2021

Publisher's Note: MDPI stays neutral with regard to jurisdictional claims in published maps and institutional affiliations.

Copyright: (c) 2021 by the authors. Licensee MDPI, Basel, Switzerland. This article is an open access article distributed under the terms and conditions of the Creative Commons Attribution (CC BY) license (https:/ / creativecommons.org/licenses/by/ $4.0 /)$.
School of Tourism and Hospitality Management, Hubei University of Economics, Wuhan 430205, China; chenqiao@hbue.edu.cn

* Correspondence: YanMao@hbue.edu.cn

\begin{abstract}
Civilized City" is the highest honor in China's urban evaluation system. This research used a quasi-natural experiment approach to evaluate how the "Civilized City" designation influence tourism economic growth. The results showed that: (1) "Civilized City" selection promotes the growth of the tourism economy, and its impact on tourism income is greater than on the number of tourists. The "Civilized City" award is more conducive to the growth of the tourism economy than other city honors; (2) the "Civilized City" honor promotes institutional supply and adjusts the allocation of capital and labor, thereby promoting the growth of the tourism economy; and (3) the analysis showed that the impact of the "Civilized City" honor on a city's tourism economy varies according to region, administrative level, and population size. The results of this research provide empirical support that city honors boost tourism economy growth and yield new evidence for cities to promote tourism development through awards and accreditations.
\end{abstract}

Keywords: city honor; “Civilized City” honor; tourism economy; natural experiment; PSM-DID

\section{Introduction}

During the last 40 years of reform and economic openness, China has made remarkable achievements in urban development following the principle of "promoting construction by evaluation". However, when cities pursue honors such as "Civilized City", "Ecological Garden City", or "National Health City", they may overlook the effect of these honors on tourism-related economic growth [1]. China's central government is continuously providing city honor guidelines and advice, attempting to encourage the transformation of city brands into tourist attractions, promoting the tourism potential of city honors, and advocating sustainable urban development.

In 2003, the Central Committee of Civilization launched the nationwide selection process for the "Civilized City" designation. The ninth category of its assessment index involves the system for civilized tourism, pretravel education, market order, and ecological environment standards. Being awarded the "Civilized City" status not only improves the environment for tourism, but also enhances the visibility and brand value of the city, and attracts domestic and international tourists. This research focuses on the question of whether the "Civilized City" designation contributes to the economic growth of tourism. Other questions addressed in this investigation regarded which institutional and other characteristics influence tourism growth, and whether the award of "Civilized City" has the same effect on tourism in all cities, or whether it varies by region, administrative level, and population size.

\section{Literature Review}

Policies and their implementation inform each other, and the research on the "Civilized City" award is ongoing. The first stream of this research has a focus on the impacts 
of the "Civilized City" designation on the economy and society in general. Shi et al. (2019) found that a "Civilized City" selection promoted the high-quality development of businesses [2]. Wu et al. (2015) pointed out that a "Civilized City" award reduced business transaction costs and increased the profit margins of private companies [3]. Liu and Liu (2021) discovered that the "Civilized City" designation promoted urban industrial structure upgrades [4]. However, some scholars have reached different conclusions. For example, Zhou (2007) found that the rigid indices used to evaluate the "Civilized City" honor increased the financial pressures on local governments [5]. Steiner et al. (2015) [6] and Nan (2016) [7] determined that "Civilized City" selection did not enhance economic growth, but limited it in the short term due to the strict requirements to protect the natural environment. Zheng and Zhang (2016) and Chen et al. (2021) found that the "Civilized City" award increased business investment in environmental governance, energy conservation, and emission reduction, and significantly inhibited profits [8,9]. Gong (2015) determined that to be rated as a "Civilized City", local governments allocated substantial economic and social resources to improve their bids, such as setting up special funds and staff organizations, thereby creating a considerable economic burden in the process [10]. Zhou and Wen (2019) suggested that to be evaluated as a "Civilized City", some cities adopted one-size-fits inspection standards, which led to disjointed urban development realities and short-term difficulties in urban industrial adjustment [11]. Manan et al. (2020) described the efforts and constraints faced by the government in order to make the city as a civilized city model, revealing responses of local citizens, and generating varied responses from the lower-, middle-, and upper-class citizens [12]. Zhang (2020) exploited China's Civilized City Award campaign as a quasi-natural experiment, and found that the environmental performance of firms located in Civilized Cities was higher than that of firms in non-Civilized Cities during the event period [13].

The impact of "evaluation and commendation" of the tourism economy is the second stream of research. Gomes and Librero-Cano (2018) discovered that the per capita tourism income for cities that were awarded the "European Capital of Culture" was 4.5\% higher than those not selected, and the effect on the city's economic growth lasted for about five years [14]. In a study of the impact of the "Cultural and Creative Parks" designation on tourism, Tan and Huang (2021) found that the number of provincial cultural and creative parks was positively correlated with tourism income [15]. In an analysis of China's key tourism cities, Shi et al. (2020) determined that the award of the "WholeRange Tourism Demonstration Zone" had a significant positive effect on urban tourism economies, the effect being stronger in cities in western than in eastern China [16]. Li et al. (2020) evaluated the impact of the "National Leisure Agriculture and Rural Tourism Model County" designation, and determined that the earlier the county was given the honor, the greater the effect on tourism-related economic growth, and the longer the benefits lasted [17]. Li et al. (2020) found that the construction of "Ecological Civilization Demonstration Areas" significantly increased per capita tourism income, and had a greater impact on cities in western China with weak economies [18]. Deng et al. (2016) also pointed out that Hainan's designation as an "International Tourism Island" did not broaden the market for tourism or increase tourism-related income [19]. Liu et al. (2018) determined that after each scenic area was approved as a "National Scenic Spot", this did not significantly promote the growth of the tourism economy [20]. Chai et.al (2021), based on the data of listed enterprises in China from 2012 to 2018, used the PSM-DID method to empirically test the impact of "Civilized City" selection on corporate social responsibility [21].

Scholars have discussed multiple dimensions of the relationship between urban honors and the economy, including environmental governance, people's livelihoods, and transaction costs. However, few studies have examined the impact of the "Civilized City" award on the tourism economy, and they have mainly used qualitative methods. An exception to this was Yang et al.'s (2020) quantitative research on the impact of urban ecological civilization construction on the tourism economy. However, due to the small sample size, the conclusions were not generalizable, limiting the usefulness of the findings. 
This research used the "Civilized City" designation in a quasi-natural experiment and applied the difference-in-differences (DID) method to examine its impact on tourismrelated economic growth. The study purpose was to enrich the literature on the relationship between urban honors and the tourism economy, and to provide new ideas for the formulation of city standards and the development of urban tourism. It aimed to measure the impact of the honorary title of "Civilized City" on tourism economies, verifying this with an econometric model. The research analyzed the approaches to using "Civilized City" selection to promote the economic growth of tourism, and made a detailed comparison of the range of effects of honor policies in cities with different characteristics including region, level, and scale.

\section{Institutional Background and Theoretical Analysis}

\subsection{Institutional Background}

In 2004, the China Civilization Committee issued the "National Civilized City Evaluation System (Trial)", which elaborated on the prerequisites, evaluation indicators, and supervision procedures for "Civilized Cities". In 2005, the "Civilized Cities" scheme was piloted with nationwide promotion. "Civilized Cities" were selected every three years, and a total of 145 cities have been approved. The "Civilized City" assessment includes several indicators, such as public morality, service levels, and the overall image of cities.

It is worth noting that since the fourth round of selections, "civilized tourism" has been added as a key assessment indicator, stating clear requirements about systems and processes for the construction, guidance, supervision, and management of tourism. Since "Civilized City" is the highest honor that can be bestowed upon a city, the evaluation criteria and procedures for becoming one are very strict. Cities can also lose the designations; since 2015, annual reviews have been conducted, and any city ranking in the lowest three in two consecutive years loses the title of "Civilized City". Thus, the "Civilized City" designation is highly sought after due to the potential benefits it brings. "Civilized City" selection is the highest-level noneconomic, competitive government scheme, so it provides an excellent case for studying the influence of city honors on the tourism economy.

\subsection{Theoretical Analysis}

The evaluation index for "Civilized Cities" had two aspects: system supply and resource allocation. This research reviewed how "Civilized City" selection alters institutional supply and resource allocation to affect tourism-related economic growth (Figure 1).

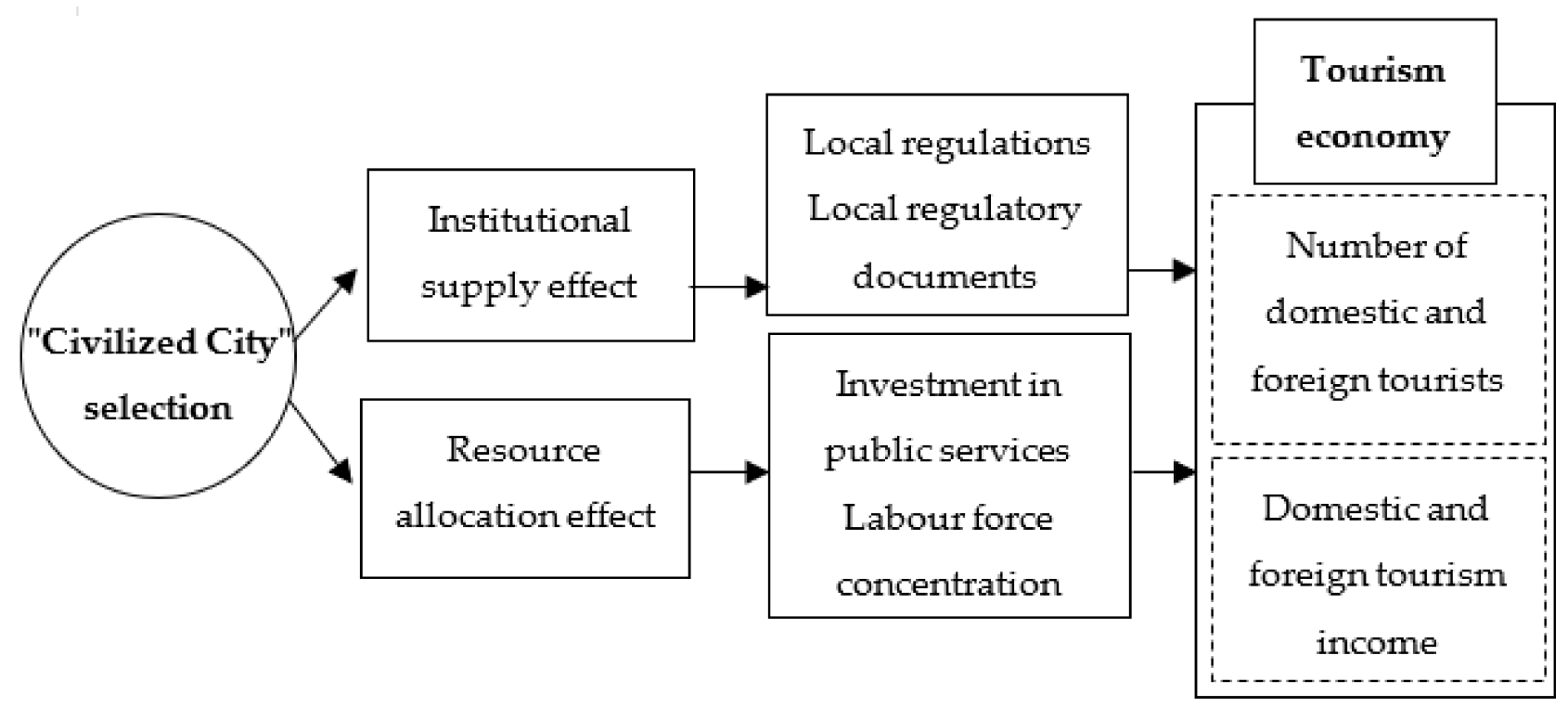

Figure 1. Effects of "Civilized City" selection on the tourism economy. 


\subsubsection{Institutional Supply Effect}

There are strict requirements about the supply of urban government, legal, ecological, and market services. Civilized cities must have effective local government, promote comprehensive law enforcement, meet high standards of administrative law enforcement management, have a streamlined administration system with structures for delegating power, and have optimized approval procedures. They must also have a fair and just environment for the rule of law, as well as a commitment to raising public awareness of the law and to make improvements to the public legal service system. Cities must invest in environmental protection measures and apply strict controls on industrial sewage, noise, and smoke emissions. "Civilized Cities" are required to have an honest and lawabiding trading environment. This includes the provision of a credit investigation system, a platform for credit information sharing, a mechanism that incentivizes businesses to maintain consumers' good faith and penalizes any breaches thereof, and a complaints and disposal mechanism for fake and faulty goods. Concerning the tourism supply system, cities are required to institutionalize a tourism volunteer service and establish a civilized tourism service standard system. In the process of building civilized cities, cities have issued many laws and regulations to promote the development of the tourism economy. Based on the above analysis, the following hypothesis was formulated:

Hypothesis 1. The Civilized City designation effectively regulates institutional supply and promotes tourism-related economic growth.

\subsubsection{Resource Allocation Effect}

According to neoclassical economic theory, capital and labor are the key factors of economic growth [21]. "Civilized City" selection can produce a more effective allocation of capital and labor.

(1) From the perspective of public services investment, "Civilized Cities" are assessed on the quality of the urban ecological environment and infrastructure, using indicators such as investment in ecological environment governance, per capita green space in parks, percentage of green land in built-up areas, and cultural facilities [22]. The "Civilized City" award also requires investment in public transportation and communication infrastructure (e.g., roads, the postal system, and telecommunications) and social services infrastructure (public facilities and public service organizations).

(2) In terms of labor resource allocation, "Civilized City " has the effect of "widely planting parasol trees (wutong), attracting the phoenix". It has the potential to encourage labor migration between cities [23]. "Civilized Cities" attract migrant workers looking for employment, and the provision of pleasant living and working environments help in retaining the existing labor force. Additionally, "Civilized City" selection helps to improve the quality of workers. Holding the "Civilized City" honor requires public education and instigation of the rule of law, the adoption of a culture of selfcultivation, and social responsibility, and also requires the government to increase investment in compulsory education and carry out free skills training, and commit to the promotion of a good image. A good credit environment is conducive to improving the quality of workers, enhancing the attraction of tourism talent in the region [24], and promoting the flow of labor resources to the tourism sector. It was proposed that:

Hypothesis 2. "Civilized City" selection promotes the growth of the tourism economy through public service investment and labor allocation.

\section{Research Design}

\subsection{Sample Selection}

Between 2005 and 2020, China invited applications for the "Civilized City" honor six times (see Appendix A, Table A1), during which 187 cities (including only prefectural-level cities and municipalities under the direct control of central government) were awarded 
the title. However, the tourism industry in 2020 was seriously affected by COVID-19, so that year was excluded from the sample. The 145 cities approved in 2005, 2009, 2011, 2015, and 2017 were assigned to the treatment group, and the cities not approved were assigned to the control group. The sampled cities were widely distributed across all provinces in China, thereby minimizing sample selection bias.

\subsection{Model Design}

Differences-in-differences(DID) is the mainstream method of policy effect evaluation. Referring to the research of Abadie (2010) [25], Manan (2020) [12], and Zhao (2020) [26], the DID analysis was set up as follows. The dummy variable consisted of the years 2006-2018, set to a value of 1 , and the years 1999-2005, set to the value of 0 . Cities selected as "Civilized Cities" between 2005 and 2018 constituted the experimental group and were allocated a value of 1 . Cities that did not participate in the "Civilized City" evaluation and those that participated but failed to be selected were allocated to the control group and assigned a value of 0 . The basic regression equation used in the model was as follows:

$$
Y_{i t}=\alpha_{0}+\alpha_{1} D I D_{i t}+\alpha_{2} D T_{i t}+\alpha_{3} D U_{i t}+\alpha_{4} C_{i t}+\mu_{i t}+v_{i t}+\varepsilon_{i t}
$$

where the explained variable $Y_{i t}$ respectively represents the per capita number of domestic tourists, domestic tourism income, numbers of foreign tourists, foreign tourism income, the total number of tourists, and the total tourism income of city $i$ in year $t$. DID $i t$, the $D I D$ estimator, represents whether city $i$ was rated as a "Civilized City" in year $t$. If it was selected to be evaluated, $D I D_{i t}=1$; otherwise, $D I D_{i t}=0 . D T_{i t}$ and $D U_{i t}$ represent the time and group dummy variables, respectively, while $\mu_{i t}$ and $v_{i t}$ represent the individual fixed and year fixed effects, respectively. $\varepsilon_{i t}$ is the standard error.

When defining the year of approval for "Civilized Cities", cities approved in the first half of the year were regarded as being approved in the previous year, and cities approved in the second half of the year were regarded as having been approved in the current year. This reflected the fact that local governments are informed of a city's successful selection as a "Civilized City" in advance of the formal announcement [10].

Following Wen and Ye's (2014) [27] method, a test model of adjustment and mediation effects was used to identify the ways by which "Civilized City" selection affected tourismrelated economic growth, as per the following equations:

$$
\begin{gathered}
Y_{i t}=\beta_{0}+\beta_{1} D I D_{i t}+\beta C_{i t}+\varepsilon_{i t} \\
M_{i t}=\delta_{0}+\delta_{1} D I D_{i t}+\delta C_{i t}+\mu_{i t} \\
Y_{i t}=\gamma_{0}+\gamma_{1} D I D_{i t}+\gamma_{2} M_{i t}+\gamma_{3} C_{i t}+\varphi_{i t} \\
Y_{i t}=\beta_{0}+\beta_{1} D I D_{i t}+\beta_{2} R_{i t}+\beta_{4} D I D_{i t} \times R_{i t}+\varepsilon_{i t}
\end{gathered}
$$

where $M_{i t}$ represents the mediating effect of institutional supply (qis), and $R_{i t}$ represents the moderating effect of public service investment (ips), accommodation and catering personnel $(a f p)$, and culture and entertainment personnel (cep), respectively. According to the principle of the Soble test, if $\delta_{1}$ and $\gamma_{2}$ both pass the significance test, the mediating effect exists, and the Soble test is not needed. If only one of $\delta_{1}$ or $\gamma_{2}$ is significant, the Soble test is required.

\subsection{Data Description}

\subsubsection{Explained Variables}

Common indicators to measure the development level of the tourism economy include the number of tourists, tourism expenditures, and the number of overnight stays [28,29], but these do not take into account the availability of tourism economy data in cities. Following Liu et al. (2020) [29] and Tan and Huang (2021) [15], six indicators were used to measure the development level of the tourism economy: per capita number of domestic tourists, per capita domestic tourism income, per capita number of foreign tourists, per capita foreign 
tourist income, per capita total number of tourists, and per capita total income of tourism (Table 1). These data were obtained from the China Tourism Statistical Yearbook 2000-2019.

Table 1. Descriptive statistics of variables used in the DID model.

\begin{tabular}{|c|c|c|c|c|}
\hline Category & Variable Name & Description & Mean & Std. Dev. \\
\hline \multirow{6}{*}{ Explained variables } & $T N$ & Total number of tourists per capita & 4.4 & 7.0 \\
\hline & TI & Total tourism income per capita & 4434.4 & 8773.5 \\
\hline & $P D T N$ & Per capita number of domestic tourists & 36.5 & 123.0 \\
\hline & PDTI & Per capita domestic tourism income & 4.3 & 7.7 \\
\hline & PFTN & Per capita number of foreign tourists & 4271.2 & 8313.7 \\
\hline & PFTI & Per capita income from foreign tourism & 4.4 & 7.01 \\
\hline Explanatory variable & $D I D$ & "Civilized City" & 0.1 & 0.3 \\
\hline \multirow{5}{*}{ Control variables } & gre & Ecological environmental protection & 0.2 & 1.4 \\
\hline & paw & Household consumption level & 128.6 & 244.7 \\
\hline & $p s p$ & Level of public administration & 114.4 & 61.0 \\
\hline & $f d i$ & Level of opening-up & 141.9 & 479.2 \\
\hline & $\operatorname{tax}$ & Transportation infrastructure & 8.1 & 10.1 \\
\hline \multirow{4}{*}{ Intermediary variables } & qis & Quality of system supply & 33.5 & 68.4 \\
\hline & ips & Investment in public services & 15.0 & 1.5 \\
\hline & afp & Accommodation and catering personnel & 8.1 & 1.6 \\
\hline & cep & Cultural and entertainment personnel & 7.9 & 1.0 \\
\hline
\end{tabular}

\subsubsection{Explanatory Variables}

Taking "Civilized City" selection as the policy impact, the grouped dummy variable $D U_{i t}$, the time dummy variable $D T_{i t}$, and the cross term $D I D_{i t}$ were used to measure the impact of "Civilized City" selection on the tourism economy.

\subsubsection{Control Variables}

$C_{i t}$ was the control variable of other factors affecting the growth of the tourism economy. The following control variables were used: (1) Ecological environmental protection (gre) was defined as the rate of green coverage in built-up areas, and reflected the extent of the urban ecological environment and commitment to environmental protection [16]. (2) Resident consumption level ( paw) reflected local tourism potential. Relatively speaking, the higher the salary level, the more opportunities to travel [30]. (3) Level of public management ( $p s p$ ) was defined by the number of public management and social security personnel. This reflected the government's public service input, management ability, and emphasis on the demand for public tourism services [31]. (4) Level of opening-up ( $f d i$ ) used actual foreign investment as a proxy variable. This reflects the degree of international tourism cooperation and market liberalization. (5) Transportation infrastructure (tax) was defined by the number of public taxis per capita, based on the assumption that accessible public transport is conducive to the development of tourism [32]. The above data were obtained from the China Tourism Statistical Yearbook, the China City Statistical Yearbook, and the EPS database (http:/ / www.epschinadata.com/; accessed on 30 June 2021).

\subsubsection{Intermediary Variables}

Fixed asset investment was used as an indicator of public service investment in tourism. The number of people employed in accommodation and catering and culture and entertainment were used as indicators of labor input in tourism. The institutional supply index was defined by the number of local laws and regulations, local government regulations, local normative documents, and working documents. This was used to measure the development of tourism. These data were obtained from the Peking University Magic database (http:/ / www.pkulaw.cn/; accessed on 13 July 2021). 


\section{Analysis and Results}

5.1. Regression Results of the Benchmark Model (DID)

The parameters of each variable were estimated using Equation (1). As can be seen in Table 2, the "Civilized City" designation played a significant role in promoting the tourism economy. The DID $D_{i t}$ coefficients from models (1)-(8) were positive and significant, indicating that the "Civilized City" honor promoted the growth of the tourism economy. Moreover, the influence of "Civilized City" selection on the number of domestic tourists was greater than that on the number of foreign tourists. One possible reason was that foreign tourists were less aware of the "Civilized City" scheme, so it had less influence on their choice of destination. From the regression coefficients, "Civilized City" selection had the greatest impact on domestic tourism income, followed by foreign tourism income, the number of domestic tourists, and the number of foreign tourists. In general, the effect of "Civilized City" selection on tourism income was significantly greater than its effect on the number of tourists.

When the city is selected as a "Civilized City", the government will widely advertise tourism through TV, Internet, and radio to attract tourists [33]. The influence coefficient of the "Civilized City" honor on tourist numbers was significant, but it is worth noting that the influence was less than that of tourism income. Receiving the "Civilized City" award can improve the urban tourism environment and the quality of tourism services [34]; stimulate tourism-related expenditure on accommodation, catering, and shopping; and improve the per capita income of destinations. Taken together, these results verified that "Civilized City" selection significantly promotes the growth of the tourism economy. 
Table 2. Influence of "Civilized City" selection on tourism-related economic growth: DID estimation.

\begin{tabular}{|c|c|c|c|c|c|c|c|c|c|c|c|c|}
\hline \multirow{2}{*}{ Variable } & \multicolumn{2}{|c|}{$P D T N$} & \multicolumn{2}{|c|}{ PDTI } & \multicolumn{2}{|c|}{ PFTN } & \multicolumn{2}{|c|}{ PFTI } & \multicolumn{2}{|c|}{$P T N$} & \multicolumn{2}{|c|}{ PTI } \\
\hline & (1) & (2) & (3) & (4) & (5) & (6) & (7) & (8) & (9) & (10) & (11) & (12) \\
\hline$D I D_{i t}$ & $\begin{array}{l}1.07 * \\
(1.84)\end{array}$ & $\begin{array}{l}0.67 * \\
(1.65)\end{array}$ & $\begin{array}{c}3032.04^{* * *} \\
(4.25)\end{array}$ & $\begin{array}{c}2464.07^{* * *} \\
(4.18)\end{array}$ & $\begin{array}{l}0.05^{* *} \\
(2.54)\end{array}$ & $\begin{array}{l}0.05^{* *} \\
(2.57)\end{array}$ & $\begin{array}{c}44.37 * * * \\
(3.52)\end{array}$ & $\begin{array}{l}39.21 * * * \\
(3.29)\end{array}$ & $\begin{array}{c}0.37 \\
(0.70)\end{array}$ & $\begin{array}{c}0.32 \\
(0.65)\end{array}$ & $\begin{array}{c}2887.33 * * * \\
(4.45)\end{array}$ & $\begin{array}{c}2880.17^{* * * *} \\
(4.40)\end{array}$ \\
\hline$p s p$ & & $\begin{array}{c}0.02^{* * *} \\
(4.31)\end{array}$ & & $\begin{array}{c}17.70 * * * \\
(3.25)\end{array}$ & & $\begin{array}{l}0.00 * \\
(1.96)\end{array}$ & & $\begin{array}{c}0.33^{* *} \\
(1.98)\end{array}$ & & $\begin{array}{c}0.02^{* * * *} \\
(4.46)\end{array}$ & & $\begin{array}{c}21.71^{* * *} \\
(3.82)\end{array}$ \\
\hline$f d i$ & & $\begin{array}{c}0.01^{* * * *} \\
(3.11)\end{array}$ & & $\begin{array}{c}0.72^{* * *} \\
(4.66)\end{array}$ & & $\begin{array}{c}0.01^{* * * *} \\
(2.92)\end{array}$ & & $\begin{array}{l}0.01^{* * *} \\
(2.32)\end{array}$ & & $\begin{array}{c}0.01^{* * * *} \\
(2.70)\end{array}$ & & $\begin{array}{c}0.77^{* * * *} \\
(4.77)\end{array}$ \\
\hline paw & & $\begin{array}{l}0.01^{* * *} \\
(2.66)\end{array}$ & & $\begin{array}{c}10.54^{* * * *} \\
(2.88)\end{array}$ & & $\begin{array}{c}0.01 \\
(1.43)\end{array}$ & & $\begin{array}{c}0.03 \\
(0.70)\end{array}$ & & $\begin{array}{c}0.01^{* * * *} \\
(3.32)\end{array}$ & & $\begin{array}{c}9.59 * * * \\
(2.83)\end{array}$ \\
\hline $\operatorname{tax}$ & & $\begin{array}{l}0.10^{*} \\
(1.70)\end{array}$ & & $\begin{array}{c}158.79 * * * \\
(2.75)\end{array}$ & & $\begin{array}{l}0.01^{*} \\
(1.76)\end{array}$ & & $\begin{array}{l}2.39 * * \\
(2.13)\end{array}$ & & $\begin{array}{c}0.07 \\
(1.08)\end{array}$ & & $\begin{array}{c}177.40^{* * *} \\
(2.71)\end{array}$ \\
\hline gre & & $\begin{array}{l}0.08^{* * *} \\
(16.24)\end{array}$ & & $\begin{array}{c}194.20^{* * *} \\
(26.33)\end{array}$ & & $\begin{array}{c}0.01^{* * * *} \\
(6.32)\end{array}$ & & $\begin{array}{c}1.02^{* * * *} \\
(6.02)\end{array}$ & & $\begin{array}{l}0.08^{* * * *} \\
(17.37)\end{array}$ & & $\begin{array}{c}202.85^{* * * *} \\
(24.55)\end{array}$ \\
\hline Control variables & & Y & & Y & & Y & & $\mathrm{Y}$ & & Y & & $\mathrm{Y}$ \\
\hline $\begin{array}{c}\text { Time fixed } \\
\text { Individual fixed }\end{array}$ & & $\mathrm{Y}$ & & $\mathrm{Y}$ & & $\mathrm{Y}$ & & $\mathrm{Y}$ & & $\mathrm{Y}$ & & $\mathrm{Y}$ \\
\hline$N$ & & 3588 & & 3541 & & 3674 & & 4108 & & 3420 & & 3423 \\
\hline
\end{tabular}

Note: the $\mathrm{T}$ value is shown in parentheses; ${ }^{* * * * * *}$, and ${ }^{*}$ indicate significance at $1 \%, 5 \%$, and $10 \%$ levels, respectively. 


\subsection{Robustness Test}

\subsubsection{PSM-DID Test}

The premise of the DID method is that the control and treatment groups have the same trend of the change before the policy's implementation. Cities that already have a well-developed tourism economy and infrastructure are more likely to be awarded the "Civilized City" honor than those that do not, which may lead to a "self-selection effect", rendering the research conclusions biased. To avoid this bias, a propensity score matching (PSM) test was used to correct for selection bias. The 145 cities that were approved as "Civilized Cities" were taken as the treatment group, and were matched year by year according to 1:1 nearest-neighbor matching with cities in the control group. After matching, the $p$-value of the difference in sample means of each control variable between the treatment and control groups after "Civilized City" awarding was not significant at the $10 \%$ level (Table 3). The PSM test was repeated using kernel, radius, and caliper matching, and the results were consistent with the nearest-neighbor matching (Table 4), indicating that the treatment and control groups met the requirements of balance, and "Civilized City" selection promoted the growth of the tourism economy; i.e., the benchmark regression results were robust and reliable.

Table 3. The results of the PSM balance test.

\begin{tabular}{|c|c|c|c|c|c|c|c|}
\hline \multirow[b]{2}{*}{ Variable } & \multirow[b]{2}{*}{ Sample } & \multicolumn{2}{|c|}{ Mean } & \multirow[b]{2}{*}{ Deviation } & \multirow{2}{*}{$\begin{array}{c}\text { Deviation } \\
\text { Reduction \% }\end{array}$} & \multirow{2}{*}{$\begin{array}{c}\mathrm{T} \\
\text { Value }\end{array}$} & \multirow[b]{2}{*}{$p>|\mathrm{t}|$} \\
\hline & & $\begin{array}{c}\text { Treatment } \\
\text { Group }\end{array}$ & $\begin{array}{l}\text { Control } \\
\text { Group }\end{array}$ & & & & \\
\hline \multirow{2}{*}{$p s p$} & Before & 115.17 & 102.73 & 20.3 & \multirow{2}{*}{39.6} & 7.28 & 0.000 \\
\hline & After & 115.17 & 122.68 & 12.3 & & 0.42 & 0.525 \\
\hline \multirow{2}{*}{$f d i$} & Before & 168.74 & 67.018 & 39.1 & \multirow[b]{2}{*}{95.0} & 14.14 & 0.000 \\
\hline & After & 168.74 & 163.61 & 2.0 & & 0.47 & 0.636 \\
\hline \multirow{2}{*}{ paw } & Before & 131.41 & 113.61 & 7.3 & \multirow{2}{*}{26.0} & 2.68 & 0.007 \\
\hline & After & 131.41 & 150.46 & -5.4 & & -1.55 & 0.122 \\
\hline \multirow[b]{2}{*}{$\operatorname{tax}$} & Before & 8.90 & 5.41 & 36.5 & \multirow{2}{*}{47.9} & 13.13 & 0.000 \\
\hline & After & 8.90 & 10.72 & -19.0 & & -1.17 & 0.243 \\
\hline \multirow{2}{*}{ gre } & Before & 0.14 & 0.12 & 10.9 & \multirow{2}{*}{52.5} & 4.16 & 0.000 \\
\hline & After & 0.14 & 0.15 & -5.2 & & -1.38 & 0.169 \\
\hline
\end{tabular}

Note: the null hypothesis $\mathrm{H} 0$ of the t-test was that the sample mean of the treatment group and control group were equal.

Table 4. PSM-DID modification results.

\begin{tabular}{ccccccc}
\hline \multirow{2}{*}{ Variable } & PDTN & PDTI & PFTN & PFTI & PTN & PTI \\
\cline { 2 - 7 } & $\mathbf{( 1 )}$ & $\mathbf{( 2 )}$ & $\mathbf{( 3 )}$ & $\mathbf{( 4 )}$ & $\mathbf{( 5 )}$ & $\mathbf{( 6 )}$ \\
\hline DID & $1.21^{*}$ & $2253.10^{* * *}$ & $0.03^{* *}$ & $27.49^{* * *}$ & 0.25 & $2762.74^{* * *}$ \\
Control variables & $(1.73)$ & $(3.35)$ & $(2.26)$ & $(3.16)$ & $(0.47)$ & $(3.75)$ \\
Time fixed & $\mathrm{Y}$ & $\mathrm{Y}$ & $\mathrm{Y}$ & $\mathrm{Y}$ & $\mathrm{Y}$ & $\mathrm{Y}$ \\
Individual fixed & $\mathrm{Y}$ & $\mathrm{Y}$ & $\mathrm{Y}$ & $\mathrm{Y}$ & $\mathrm{Y}$ & $\mathrm{Y}$ \\
\hline$R^{2}$ & 0.39 & 0.44 & 0.18 & 0.19 & 0.45 & 0.41 \\
$N$ & 3742 & 3710 & 3903 & 4473 & 3551 & 3559 \\
\hline
\end{tabular}

Note: the T value is shown in parentheses; ${ }^{* * *}, * *$, and ${ }^{*}$ indicate significance at $1 \%, 5 \%$, and $10 \%$ levels, respectively.

\subsubsection{The Placebo Test}

The placebo test was carried out for a randomized treatment group and a control group. The cities that had been approved as "Civilized Cities" were taken as the new control group, and the approval time remained unchanged. Assuming that $n$ cities were approved as "Civilized Cities" in the year $t, n$ cities were randomly selected from those that had not been approved as "Civilized Cities" in the same year or before and were allocated to the treatment group. The dual difference test was repeated 1000 times, and the mean 
coefficient of each variable was calculated. All values were less than the corresponding $D I D_{i t}$ coefficient $(0.01,6.40,0.01,32.32,-0.01$, and 2556.23$)$ of the control variable model in Table 1, indicating that "Civilized City" selection played a significant role in promoting the growth of the tourism economy. The placebo test was also applied to the time when cities gained the "Civilized City" honor. Assuming that the approved "Civilized Cities" remain unchanged and city $i$ was approved in year $t$, a year was randomly selected as the approved time from 1999 to $t-1$, and a new regression coefficient of DID $D_{i t}$ was calculated based on the results of the new sample estimation model. After 1000 repetitions of the test, the mean values of the $D I D_{i t}$ coefficients $(0.02,31.67,0.01,12.31,-0.01$, and 2577.75$)$ decreased by about $30 \%$ compared with the results shown in Table 1, indicating that a random advance approval time led to a significant decline in the positive effect of "Civilized City" selection on tourism economic growth. These results supported the proposition that the approval of "Civilized City" promoted the growth of the tourism economy, and the benchmark regression results were reliable.

\subsubsection{Excluding Other Policy Influences}

It was important to ascertain whether changes to the tourism economy of each city resulted only from its selection as a "Civilized City", or whether other honorary titles, such as "Excellent Tourism City", "Historical and Cultural City", or "Smart City" also had an impact on the tourism economy. Between 1998 and 2010, 337 cities were awarded the title of "Excellent Tourism City". It has been shown that the honor of "Excellent Tourism City" can significantly increase a city's attraction to tourists [35]. To test its influence, "Excellent Tourism City" was included in the model, and assigned cities with the title of "Excellent Tourism City" and "Civilized City" were given a value of 1 , and the other cities a value of 0 (in 2005, there were 2 cities with the titles of "Excellent Tourism City" and "Civilized City", and in 2020, there were 60 cities with the titles of "Excellent Tourism City" and "Civilized City"). Together, these constituted the dummy grouped variable $D U_{i t}$. For the dummy time variable, $D T_{i t}$, years in the period 1999-2010 were assigned a value of 1 , and other years a value of $0 . L_{1}$ represented the cross-product of the dummy grouping and dummy time variables; that is, the tourism economic growth effect of the "Excellent Tourism City" honor.

The influence of the "Historical and Cultural City" honor on the growth of the tourism economy was also determined. The State Council has awarded this honor to 162 cities since 1982. Historically, this has been an important honor for a city to attract foreign tourism, so it was incorporated into the model. $L_{2}$ represents the cross-product term of the grouping and time dummy variables used to explore the influence of the "Historical and Cultural City" policy on the development of the tourism economy.

Many studies have shown that tourists increasingly attach importance to the availability of information in their chosen destination [36,37]. Between 2012 and 2014, the Ministry of Housing and Urban-Rural Development announced three batches of 290 "Smart Cities". "Smart City" was included in the benchmark regression, and the cross-product term $L_{3}$ comprising the time and grouped dummy variables were added to the regression model as follows:

$$
Y_{i t}=\alpha_{0}+\alpha_{1} D I D_{i t}+\alpha_{2} L_{1}+\alpha_{3} L_{2}+\alpha_{4} L_{3}+\lambda C_{i t}+\mu_{i t}+v_{i t}+\varepsilon_{i t}
$$

According to Equation (5), after $L_{1}, L_{2}$, and $L_{3}$ were included in the benchmark model, if the effect coefficient of the "Civilized City" dummy variable, DID $D_{i t}$, on tourism-related economic growth was not significant, the conclusion that "Civilized City" selection could significantly promote tourism economic growth was biased. In other words, the growth effect on the tourism economy may have been from receiving other honors. If the dummy variable $D I D_{i t}$ was significant, this indicated that "Civilized City" selection promoted the growth of the tourism economy.

The results in Table 5 show that the DID $D_{i t}$ coefficient in models (1)-(6) was still significant after the dummy variables representing the effect of "Excellent Tourism City", 
"Famous Historical and Cultural City", and "Smart City" honor were added. This indicated that "Civilized City" selection did promote the growth of the tourism economy. The "Excellent Tourism City" honor had a significant impact on tourism income, total tourism income, the number of foreign tourists, and the total number of tourists. "Famous Historical and Cultural City" and "Smart City" had a positive impact on the number of tourists and tourism income, but it was not significant. It can be seen that the honorary title of "Excellent Tourism City" was more attractive to tourists than "Famous Historical and Cultural City" or "Smart City", and had a stronger role in promoting tourism-related economic growth.

Table 5. The impact of other honors on the tourism economy.

\begin{tabular}{|c|c|c|c|c|c|c|}
\hline \multirow{2}{*}{ Variable } & PDTN & PDTI & $P F T N$ & PFTI & $P T N$ & PTI \\
\hline & (1) & (2) & (3) & (4) & (5) & (6) \\
\hline$D I D_{i t}$ & $\begin{array}{c}1.83^{* * *} \\
(3.95)\end{array}$ & $\begin{array}{c}4091.65^{* * *} \\
(4.77)\end{array}$ & $\begin{array}{c}54.41^{* * *} \\
(2.90)\end{array}$ & $\begin{array}{c}67.53^{* *} \\
(2.23)\end{array}$ & $\begin{array}{c}1.44^{* * *} \\
(2.79)\end{array}$ & $\begin{array}{c}4661.54 \text { *** } \\
(4.58)\end{array}$ \\
\hline$L_{1}$ & $\begin{array}{c}1.33 \\
(1.24)\end{array}$ & $\begin{array}{c}3606.34^{* * * *} \\
(2.86)\end{array}$ & $\begin{array}{c}42.78 * \\
(1.85)\end{array}$ & $\begin{array}{l}41.24 \\
(1.40)\end{array}$ & $\begin{array}{c}1.90^{* * *} \\
(2.93)\end{array}$ & $\begin{array}{c}4038.29 * * * \\
(-2.80)\end{array}$ \\
\hline$L_{2}$ & $\begin{array}{c}0.80 \\
(0.80)\end{array}$ & $\begin{array}{c}669.04 \\
(0.47)\end{array}$ & $\begin{array}{l}21.16 \\
(1.38)\end{array}$ & $\begin{array}{l}19.95 \\
(1.18)\end{array}$ & $\begin{array}{c}0.36 \\
(0.46)\end{array}$ & $\begin{array}{c}411.14 \\
(0.29)\end{array}$ \\
\hline$L_{3}$ & $\begin{array}{c}0.66 \\
(0.74)\end{array}$ & $\begin{array}{c}664.97 \\
(0.66)\end{array}$ & $\begin{array}{c}6.91 \\
(0.57)\end{array}$ & $\begin{array}{c}6.58 \\
(-0.30)\end{array}$ & $\begin{array}{c}0.05 \\
(0.11)\end{array}$ & $\begin{array}{c}939.58 \\
(0.85)\end{array}$ \\
\hline Control variables & $\mathrm{Y}$ & $\mathrm{Y}$ & $\mathrm{Y}$ & $\mathrm{Y}$ & $\mathrm{Y}$ & $\mathrm{Y}$ \\
\hline Time fixed & $\mathrm{Y}$ & $\mathrm{Y}$ & $\mathrm{Y}$ & $\mathrm{Y}$ & $\mathrm{Y}$ & Y \\
\hline Individual fixed & $\mathrm{Y}$ & $\mathrm{Y}$ & $\mathrm{Y}$ & $\mathrm{Y}$ & $\mathrm{Y}$ & $\mathrm{Y}$ \\
\hline$N$ & 3588 & 3541 & 3674 & 4108 & 3420 & 3423 \\
\hline$R^{2}$ & 0.41 & 0.45 & 0.23 & 0.20 & 0.45 & 0.44 \\
\hline
\end{tabular}

After the three other city honors were included in the model, the $D I D_{i t}$ coefficient representing the impact of "Civilized City" selection on the tourism economy was significantly greater than in the benchmark regression, indicating that the effect of the "Civilized City" honor on tourism economic growth was underestimated when considered alone. The above conclusions did not contradict the benchmark conclusions, but suggested that multiple policies may create a combined effect on tourism.

\section{Mediation and Moderation Tests}

\subsection{System Supply Channels: Local Regulations and Management Measures}

Laws, regulations, and government management systems are important guarantees for the sustainable development of tourism. Studies have shown that a "Civilized City" significantly improves in terms of market order, government governance, and legal system by system construction [10]. Some 939 regulatory documents issued by various cities from 1999 to 2019, including 4 local regulations, 207 local normative documents, and 728 local working documents, were gathered for the terms "Civilized City" and "city creation". To eliminate differences in city size, the number of documents per 10,000 people was used. Following Wen and Ye (2014) [27], a mediating-effect model was constructed and tested in which the quantity of institutional supply (qis) in each city, defined as the number of documents mentioning the aforementioned search terms, was treated as the intermediary variable.

Table 6 shows the mediating effect of "Civilized City" selection on tourism economic growth. The core explanatory variable $D I D_{i t}$ coefficient $\delta_{1}$ was significantly positive at the $1 \%$ level, indicating that "Civilized City" selection promoted the growth of urban institutional supply, and provided more institutional dividends for tourism development. Furthermore, the coefficient $\gamma_{2}$ of cep in models (2) and (4) was also significantly positive at the $1 \%$ level. Since both $\delta_{1}$ and $\gamma_{2}$ were significant, the Sobel test was not required. The 
above results indicated that "Civilized City" selection promoted the growth of the tourism economy by increasing urban institutional supply, which supported Hypothesis 2.

Table 6. Test of the mediating effect of institutional supply.

\begin{tabular}{ccccc}
\hline \multirow{2}{*}{ Variable } & cep & PTN & cep & PTI \\
\cline { 2 - 5 } & $\mathbf{( 1 )}$ & $\mathbf{( 2 )}$ & $\mathbf{( 3 )}$ & $\mathbf{( 4 )}$ \\
\hline \multirow{2}{*}{ DID $i t$} & $1.50^{* * *}$ & $1.75^{* * * *}$ & $1.50^{* * *}$ & $4842.83^{* * * *}$ \\
& $(7.70)$ & $(3.61)$ & $(7.70)$ & $(6.69)$ \\
qis & & $0.27^{* * *}$ & & $290.07^{* * *}$ \\
Control variables & $\mathrm{Y}$ & $(4.09)$ & $\mathrm{Y}$ & $(3.18)$ \\
Time fixed & $\mathrm{Y}$ & $\mathrm{Y}$ & $\mathrm{Y}$ & $\mathrm{Y}$ \\
Individual fixed & $\mathrm{Y}$ & $\mathrm{Y}$ & $\mathrm{Y}$ & $\mathrm{Y}$ \\
\hline$N$ & 4530 & 3414 & 4530 & 3416 \\
$R^{2}$ & 0.33 & 0.38 & 0.33 & 0.35 \\
\hline
\end{tabular}

Note: The $\mathrm{T}$ value is shown in parentheses; ${ }^{* * *},{ }^{* *}$, and ${ }^{*}$ indicate significance at $1 \%, 5 \%$, and $10 \%$ levels, respectively.

\subsection{Resource Allocation Channels: Capital and Labor}

A resource allocation regulation effect model of "Civilized City" selection was constructed using the method described in Section 5.1, the results of which are shown in Table 7. The regression coefficients of public service investment (ips) and DID it were significantly positive at the $1 \%$ level, indicating that "Civilized City" selection improved public service investment and promoted the growth of tourist numbers and tourism income. In addition, accommodation catering personnel $(a f p)$, culture and entertainment personnel (cep) also passed the significance test. This showed that "Civilized City" selection accelerated the transfer and agglomeration of capital and labor to tourism by adjusting the investment in public services and allocating labor resources to the tourism sector, thus promoting the growth of the tourism economy.

Table 7. Test of the moderating effect of capital and labor resource allocation.

\begin{tabular}{|c|c|c|c|c|c|c|c|c|}
\hline \multirow{3}{*}{ Variable } & $P T N$ & PTI & \multirow{3}{*}{ Variable } & $P T N$ & PTI & \multirow{3}{*}{ Variable } & PTN & PTI \\
\hline & (1) & (2) & & (3) & (4) & & (5) & (6) \\
\hline & \multicolumn{2}{|c|}{$\begin{array}{c}\text { Investment } \\
\text { in Public Services }\end{array}$} & & \multicolumn{2}{|c|}{$\begin{array}{l}\text { Accommodation and } \\
\text { Catering Employees }\end{array}$} & & \multicolumn{2}{|c|}{$\begin{array}{l}\text { Cultural and } \\
\text { Entertainment Employees }\end{array}$} \\
\hline$D I D_{i t}$ & $\begin{array}{l}36.06 * * * \\
(5.62)\end{array}$ & $\begin{array}{l}8.8 \times 10^{4 * * *} \\
\quad(10.68)\end{array}$ & $D I D_{i t}$ & $\begin{array}{l}1.53 \\
(0.78)\end{array}$ & $\begin{array}{l}1.2 \times 10^{4 * * *} \\
(4.62)\end{array}$ & $D I D_{i t}$ & $\begin{array}{l}8.62 * * * \\
(3.34)\end{array}$ & $\begin{array}{c}2.3 \times 10^{4 * * *} \\
(6.80)\end{array}$ \\
\hline$i p s \times D I D_{i t}$ & $\begin{array}{l}2.20^{* * *} \\
(5.79)\end{array}$ & $\begin{array}{c}5418.43 * * * \\
(11.13)\end{array}$ & afp $\times D I D_{i t}$ & $\begin{array}{l}0.39 * \\
(1.83)\end{array}$ & $\begin{array}{l}1830.11^{* * *} \\
(6.55)\end{array}$ & cep $\times D I D_{i t}$ & $\begin{array}{c}1.23 * * * \\
(4.12)\end{array}$ & $\begin{array}{c}3264.92^{* * *} \\
(8.22)\end{array}$ \\
\hline ips & $\begin{array}{l}1.20^{* * *} \\
(14.82)\end{array}$ & $\begin{array}{c}1174.70^{* * *} \\
(12.06)\end{array}$ & $a f p$ & $\begin{array}{c}0.53^{* * *} \\
(3.93)\end{array}$ & $\begin{array}{c}707.06^{* * *} \\
(4.08)\end{array}$ & cep & $\begin{array}{c}1.13^{* * *} \\
(4.43)\end{array}$ & $\begin{array}{c}1374.27^{* * *} \\
(4.12)\end{array}$ \\
\hline Control variables & $\mathrm{Y}$ & $\mathrm{Y}$ & $\mathrm{Y}$ & $\mathrm{Y}$ & Control variables & $\mathrm{Y}$ & $\mathrm{Y}$ & $\mathrm{Y}$ \\
\hline Time fixed & $\mathrm{Y}$ & $\mathrm{Y}$ & Y & $\mathrm{Y}$ & Time fixed & $\mathrm{Y}$ & $\mathrm{Y}$ & $\mathrm{Y}$ \\
\hline Individual fixed & $\mathrm{Y}$ & $\mathrm{Y}$ & $\mathrm{Y}$ & $\mathrm{Y}$ & Individual fixed & $\mathrm{Y}$ & $\mathrm{Y}$ & $\mathrm{Y}$ \\
\hline$N$ & 3289 & 3315 & $N$ & 3149 & 3074 & $N$ & 3154 & 3079 \\
\hline$R^{2}$ & 0.39 & 0.38 & $R^{2}$ & 0.37 & 0.35 & $R^{2}$ & 0.38 & 0.36 \\
\hline
\end{tabular}

Note: The $\mathrm{T}$ value is shown in parentheses; ${ }^{* * *},{ }^{* *}$, and ${ }^{*}$ indicate significance at $1 \%, 5 \%$, and $10 \%$ levels, respectively.

\section{Discussion: Tests for Differing Effects of City Honors}

\subsection{Differences by Region}

Compared with cities in eastern China, central and western cities have fewer tourism transportation facilities, tourism resource endowments, and lower tourism service levels, so the influence of "Civilized City" selection on the tourism economy might differ. The urban location classification standards by administrative divisions of the People's Republic of China (2020) informed the analysis of differing effects of "Civilized Cities" on the tourism 
economy in different regions. The impact of the "Civilized City" honor was significantly greater on cities in the eastern region than those in central and western regions (Table 8). This suggested potential tourists were more willing to travel to cities with good economies, excellent transportation facilities, and high service levels, and where there were many tourist activities. The policy effect of "Civilized Cities" on central and western cities may have been smaller than that on eastern cities due to the conditions of tourism resources, the absorptive capacity of tourism investment, and time-lag effects. Finally, the economies of western cities are mainly based on primary and secondary industries, and the tourism economy is relatively small. "Civilized City" selection has not yet delivered sufficient improvements to local infrastructure, tourism facilities, or service quality to promote the growth of the tourism economy.

Table 8. Test of the impacts of the "Civilized City" honor in different regions.

\begin{tabular}{ccccccc}
\hline \multirow{2}{*}{ Variable } & PDTN & PDTI & PFTN & PFTI & PTN & PTI \\
\cline { 2 - 7 } & $\mathbf{( 1 )}$ & $\mathbf{( 2 )}$ & $\mathbf{( 3 )}$ & $\mathbf{( 4 )}$ & $\mathbf{( 5 )}$ & $\mathbf{( 6 )}$ \\
\hline \multirow{2}{*}{ DID $D_{i t}^{\text {east }}$} & 0.78 & $3392.77^{* * *}$ & $0.07^{* * *}$ & $54.71^{* * *}$ & 0.73 & $3800.94^{* * *}$ \\
DID & $(1.38)$ & $(3.80)$ & $(3.10)$ & $(3.28)$ & $(1.45)$ & $(4.06)$ \\
& 0.69 & 879.83 & 0.01 & 3.26 & 0.78 & 1087.54 \\
DIt & $(1.13)$ & $(1.11)$ & $(0.75)$ & $(1.09)$ & $(1.28)$ & $(1.42)$ \\
Cont & 1.70 & $2397.74^{*}$ & 0.02 & 5.04 & 0.72 & $2395.64^{*}$ \\
Control variables & $(1.00)$ & $(1.84)$ & $(1.33)$ & $(0.75)$ & $(0.49)$ & $(1.78)$ \\
Time fixed & $\mathrm{Y}$ & $\mathrm{Y}$ & $\mathrm{Y}$ & $\mathrm{Y}$ & $\mathrm{Y}$ & $\mathrm{Y}$ \\
Individual fixed & $\mathrm{Y}$ & $\mathrm{Y}$ & $\mathrm{Y}$ & $\mathrm{Y}$ & $\mathrm{Y}$ & $\mathrm{Y}$ \\
\hline$N$ & 3742 & 3710 & 3903 & 4473 & 3551 & 3559 \\
$R^{2}$ & 0.39 & 0.44 & 0.18 & 0.19 & 0.45 & 0.41 \\
\hline
\end{tabular}

Note: The T value is shown in parentheses; ${ }^{* * *},{ }^{* *}$, and ${ }^{*}$ indicate significance at $1 \%, 5 \%$, and $10 \%$ levels, respectively.

\subsection{Differences by Administrative Levels}

Under China's unique political and administrative system, industrial policies vary according to the administrative level. For example, high-level administrative cities such as provincial capitals and subprovincial cities (since many subprovincial cities belong to provincial capital cities, this study merged the subprovincial cities into the sample of provincial capital cities and did not classify them separately), which have a higher honor and are more valued, enjoy more policy dividends, and have more capital and labor resources. Cities were divided into provincial capital cities and nonprovincial capital cities to study the effect of administrative level on the impact of "Civilized City" selection on the growth of the tourism economy.

The results showed that in low-level, nonprovincial capital cities, the positive effect of "Civilized City" selection on the tourism economy was more significant. In provincial capitals, all aspects of the tourism economy except the number of foreign tourists failed to pass the significance test (Table 9). One possible reason was that other resource allocation policies and market efficiency were lower in nonprovincial capital cities, so the award of the "Civilized City" honor had a profound effect on tourism development. "Civilized city" selection is essential to tourism development in nonprovincial capital cities, whereas it is just one of many beneficial policies in high-level provincial capital cities. 
Table 9. Test of the impacts of the "Civilized City" honor at different administrative levels.

\begin{tabular}{ccccccc}
\hline \multirow{2}{*}{ Variable } & PDTN & PDTI & PFTN & PFTI & PTN & PTI \\
\cline { 2 - 7 } & $\mathbf{( 1 )}$ & $\mathbf{( 2 )}$ & $\mathbf{( 3 )}$ & $\mathbf{( 4 )}$ & $\mathbf{( 5 )}$ & $\mathbf{( 6 )}$ \\
\hline \multirow{2}{*}{ DID provincial capital city } & 0.13 & 1446.67 & $0.04^{*}$ & 31.86 & 0.23 & 1672.56 \\
it & $(0.17)$ & $(1.66)$ & $(1.73)$ & $(1.35)$ & $(0.29)$ & $(1.55)$ \\
DID $D_{\text {it }}^{\text {Non-provincial capital city }}$ & 0.55 & $1877.84^{* * *}$ & $0.04^{*}$ & $29.30 * * *$ & 0.06 & $2382.58^{* * *}$ \\
Control variables & $(1.11)$ & $(3.00)$ & $(1.95)$ & $(2.70)$ & $(0.11)$ & $(3.61)$ \\
Time fixed & $\mathrm{Y}$ & $\mathrm{Y}$ & $\mathrm{Y}$ & $\mathrm{Y}$ & $\mathrm{Y}$ & $\mathrm{Y}$ \\
Individual fixed & $\mathrm{Y}$ & $\mathrm{Y}$ & $\mathrm{Y}$ & $\mathrm{Y}$ & $\mathrm{Y}$ & $\mathrm{Y}$ \\
$\mathrm{N}$ & $\mathrm{Y}$ & $\mathrm{Y}$ & $\mathrm{Y}$ & $\mathrm{Y}$ & $\mathrm{Y}$ & $\mathrm{Y}$ \\
\hline$R^{2}$ & 3742 & 3710 & 3903 & 4473 & 3551 & 3559 \\
& 0.39 & 0.44 & 0.18 & 0.19 & 0.45 & 0.41 \\
\hline
\end{tabular}

Note: The T value is shown in parentheses; ${ }^{* * *},{ }^{* *}$, and ${ }^{*}$ indicate significance at $1 \%, 5 \%$, and $10 \%$ levels, respectively.

\subsection{Differences by Population Size}

The effects of the "Civilized City" honor on different-sized cities was also investigated. Due to the small number of super cities and small cities in the sample, only medium-sized, large, and megacities were included in the analysis. According to the Notice on Adjusting the Classification Standard of City Size issued by The State Council in 2014, cities are divided into five categories according to the size of the permanent urban population: super cities (more than 10 million), megacities (5-10 million), large cities (1-5 million), mediumsized cities (0.5-1 million), and small cities (less than 500,000). The results shown in Table 10 indicate that the effect of the "Civilized City" honor on the growth of the tourism economy was greater in megacities than in large and medium-sized cities.

Table 10. Test of the impacts of the "Civilized City" honor by population size.

\begin{tabular}{|c|c|c|c|c|c|c|}
\hline \multirow{2}{*}{ Variable } & PDTN & PDTI & PFTN & PFTI & $P T N$ & PTI \\
\hline & (1) & (2) & (3) & (4) & (5) & (6) \\
\hline$D I D_{i t}^{\text {mega cities }}$ & $\begin{array}{l}0.99 * * \\
(2.31)\end{array}$ & $\begin{array}{c}2779.02 \text { *** } \\
(3.35)\end{array}$ & $\begin{array}{l}0.02^{* * *} \\
(3.18)\end{array}$ & $\begin{array}{l}25.92 * * * \\
(2.82)\end{array}$ & $\begin{array}{l}0.97^{* *} \\
(2.27)\end{array}$ & $\begin{array}{c}2773.98 * * * \\
(2.94)\end{array}$ \\
\hline$D I D_{i t}^{\text {large cities }}$ & $\begin{array}{c}0.56 \\
(0.77)\end{array}$ & $\begin{array}{c}2057.84^{* * *} \\
(2.68)\end{array}$ & $\begin{array}{l}0.06 * \\
(1.68)\end{array}$ & $\begin{array}{c}50.44^{* *} \\
(2.18)\end{array}$ & $\begin{array}{c}0.21 \\
(0.26)\end{array}$ & $\begin{array}{c}2772.37^{* * *} \\
(3.42)\end{array}$ \\
\hline$D I D_{i t}^{\text {medium-sized cities }}$ & $\begin{array}{l}11.20 * \\
(1.76)\end{array}$ & $\begin{array}{c}1021.65 \\
(0.67)\end{array}$ & $\begin{array}{c}0.13 \\
(0.39)\end{array}$ & $\begin{array}{l}159.33 \\
(1.33)\end{array}$ & $\begin{array}{l}12.44 * \\
(1.89)\end{array}$ & $\begin{array}{l}157.77 \\
(0.02)\end{array}$ \\
\hline Control variables & $\mathrm{Y}$ & $\mathrm{Y}$ & $\mathrm{Y}$ & $\mathrm{Y}$ & $\mathrm{Y}$ & $\mathrm{Y}$ \\
\hline Time fixed & $\mathrm{Y}$ & $\mathrm{Y}$ & $\mathrm{Y}$ & $\mathrm{Y}$ & $\mathrm{Y}$ & $\mathrm{Y}$ \\
\hline Individual fixed & $\mathrm{Y}$ & Y & $\mathrm{Y}$ & $\mathrm{Y}$ & $\mathrm{Y}$ & $\mathrm{Y}$ \\
\hline$N$ & 1135 & 1095 & 1190 & 1296 & 1096 & 1068 \\
\hline$R^{2}$ & 0.76 & 0.73 & 0.35 & 0.41 & 0.76 & 0.72 \\
\hline
\end{tabular}

Note: The T value is shown in parentheses; ${ }^{* * *},{ }^{* *}$, and ${ }^{*}$ indicate significance at $1 \%, 5 \%$, and $10 \%$ levels, respectively.

Megacities are rich in the financial, material, and labor resources needed to construct a "Civilized City". "Civilized City" selection is not random, and most ordinary prefecturelevel cities do not have the resources necessary to be awarded the honor. "Civilized City" selection requires a city's per capita GDP to be higher than the national average for two consecutive years. As such, megacities are more likely to be suitable candidates for the "Civilized City" honor. The above conclusions indicated that the promotion effect of urban honors on tourism-related economic growth differed significantly based on the geographical location, administrative level, and population size of cities.

\section{Conclusions}

Using panel data from 289 cities in China from 1999 to 2019, a DID method was used to assess the impact of "Civilized City" selection on the growth of cities' tourism economies. There were four major conclusions: (1) Receiving the honor of "Civilized City" was found 
to significantly promote the growth of the tourism economy. The growth of tourism income was significantly greater than the growth of the number of tourists. The "Civilized City" designation improved the urban tourism environment, enhanced the quality of tourism service, stimulated the consumption by tourists, and then promoted the growth of per capita tourism income; (2) the "Civilized City" honor was more conducive to the growth of tourism than the "Excellent Tourism City", "Famous Historical and Cultural City", or "Smart City" honors, suggestive of a long-term underestimation of the growth effect of the "Civilized City" honor; (3) "Civilized City" selection increased institutional supply and levels of investment and labor, which facilitated the development of tourism by improving the business environment for tourism, accelerating the accumulation of capital and labor in the tourism industry, and promoting the growth of the tourism economy; and (4) further analysis showed that the promotion effect of the "Civilized City" honor on the tourism economy was not homogenous across all cities. Significant differences were found among cities, according to their locations, administrative levels, and population size.

Based on the above findings, the following policy implications were developed. First, all cities should be aware of the promotion effect of the "Civilized City" honor on the growth of the tourism economy. As "Civilized City" is the most valuable city brand, the government should publicize "Civilized Cities" more widely to attract more domestic and international tourists, and contribute to the sustainable growth of the tourism economy. City honor shows the vitality, potential [38], and competitiveness of a city's future development [39]. Government departments should make full use of the city honor, carry out tourism publicity activities, improve the attractiveness and visibility of the city [40], and promote the development of tourism and economic development. Second, the connection between different city honors should be strengthened. The policy priorities associated with each city honor should complement one another so that the growth effect of each can be maximized and the development principle of "promoting construction by evaluation" can be adopted in the tourism sector. The government should formulate a more perfect award system for civilized cities, improve the enthusiasm of cities to participate in the selection of "Civilized Cities" [41], and pay attention to the complementarity between the honor of "Civilized City" and other city honors. For example, "National Forest City", "Garden City", "Excellent Tourism City", "Historical and Cultural City", and all other kinds of honors should be developed together to promote the growth of tourism economy.

Third, the "Civilized City" selection should be used to promote tourism economic growth. Governments should improve the quality and infrastructure of tourism services, establish rules and regulations for tourism development, and promote the flow and agglomeration of investment and labor resources into the tourism sector. Scholars have found that "Civilized City" selection helps improve transportation infrastructure [42], ecological environment, and civilized tourism [43]. In particular, the evaluation system of civilized cities puts forward clear requirements for civilized tourism (see Appendix A, Table A2), which lays a solid foundation for the development of tourism.

Fourth, it should be acknowledged that "Civilized City" selection will not lead to the rapid growth of the tourism economy in all cities in China. This research has shown the significant heterogeneity in the growth effect of the "Civilized City" honor on the tourism economy in cities from different regions and with different administrative levels and population sizes. Cities in western regions, nonprovincial capital cities, and small and medium-sized cities should take the "Civilized City" selection as an opportunity and make full use of the policy dividends to accelerate the development of tourism.

This study had some limitations, as it mainly used city-level samples to address the debate regarding "Civilized Cities" selection to promote tourism economic growth from a relatively macro perspective, but lacked discussion on a more micro level. In future research, it will be an important improvement to further study the micromechanism and welfare effect of urban honors promoting tourism economic growth by using microdata of prefectures, districts, and towns. 
Author Contributions: Conceptualization, Q.C. and Y.M.; methodology, Q.C. and Y.M.; software, Q.C. and Y.M.; formal analysis, Q.C. and Y.M.; writing - original draft preparation, Q.C.; writingreview and editing, Q.C. and Y.M.; visualization, Q.C. and Y.M.; funding acquisition, Q.C. and Y.M. All authors have read and agreed to the published version of the manuscript.

Funding: This study was supported by the National Natural Science Foundation of China (grant nos. 41871137 and 41867071); the Scientific Research Cultivation Project 2020 of the Hubei University of Economics (grant no. PYYB202009); the Wuhan Social Science Federation (grant no. WHSKL2021149); and the Major Project of High-Resolution Earth Observation System (grant no. GFZX0404130302).

Institutional Review Board Statement: Not applicable.

Informed Consent Statement: Not applicable.

Data Availability Statement: All data required to support this research is already presented in this manuscript.

Acknowledgments: We sincerely thank the editor and anonymous referees, whose remarks have been very constructive and inspiring in preparing the final version of the paper.

Conflicts of Interest: The authors declare no conflict of interest.

Appendix A

Table A1. List of civilized cities.

\begin{tabular}{|c|c|c|c|c|}
\hline 2005 & 2008 & 2011 & 2014 & 2017 \\
\hline Baotou & Daqing & Tangshan & Shenyang & Shijiazhuang \\
\hline Dalian & Nanjing & Changzhi & Harbin & Qinhuangdao \\
\hline Ningbo & Suzhou & Ordos & Wuxi & Handan \\
\hline Xiamen & Nantong & Changchun & Zhenjiang & Tongliao \\
\hline Qingdao & Maanshan & Changzhou & Taizhou & Anshan \\
\hline Yantai & Huizhou & Yangzhou & Wenzhou & Panjin \\
\hline Shenzhen & Dongguan & Hangzhou & Shaoxing & Yichun \\
\hline \multirow[t]{27}{*}{ Zhongshan } & Nanning & Jiaxing & Hefei & Xuzhou \\
\hline & Chengdu & Fuzhou & Wuhu & Suqian \\
\hline & & Zibo & Tongling & Huzhou \\
\hline & & Linyi & Sanming & Taizhou \\
\hline & & Zhengzhou & Quanzhou & Lishui \\
\hline & & Luoyang & Zhangzhou & Bengbu \\
\hline & & Yichang & Nanchang & Huaibei \\
\hline & & Changsha & Dongying & Anqing \\
\hline & & Changde & Weifang & Xuancheng \\
\hline & & Guangzhou & Weihai & Putian \\
\hline & & Jiangmen & Puyang & Longyan \\
\hline & & Mianyang & Xuchang & Ganzhou \\
\hline & & Guiyang & Wuhan & Ji'an \\
\hline & & Lhasa & Zhuzhou & Jinan \\
\hline & & Yinchuan & Yueyang & Rizhao \\
\hline & & Karamay & Zhuhai & Xinxiang \\
\hline & & & Foshan & Zhumadian \\
\hline & & & Guang'an & Xiangtan \\
\hline & & & Xi'an & Haikou \\
\hline & & & Baoji & Luzhou \\
\hline & & & Jinchang & Suining \\
\hline & & & & Zunyi \\
\hline & & & & Xianyang \\
\hline & & & & Jiayuguan \\
\hline & & & & Xining \\
\hline & & & & Shizuishan \\
\hline & & & & Urumqi \\
\hline
\end{tabular}


Table A2. Requirements for civilized tourism.

\begin{tabular}{|c|c|c|}
\hline \multirow{5}{*}{ II-9 Civilization tourism } & \multirow[b]{2}{*}{$\begin{array}{l}\text { III-16 System and } \\
\text { mechanism building }\end{array}$} & $\begin{array}{l}\text { (1) Set up departmental joint meetings } \\
\text { or work leading groups; form a } \\
\text { coordinated and linked working system }\end{array}$ \\
\hline & & $\begin{array}{l}\text { (2) Implement the interim measures for } \\
\text { the administration of records of } \\
\text { uncivilized behaviors in tourism; } \\
\text { establish a notification mechanism for } \\
\text { uncivilized tourism information }\end{array}$ \\
\hline & \multirow{3}{*}{$\begin{array}{l}\text { III-17 Education, } \\
\text { guidance, supervision, } \\
\text { and administration }\end{array}$} & $\begin{array}{l}\text { (3) News media should provide } \\
\text { positive guidance and negative } \\
\text { exposure of tourists' behavior }\end{array}$ \\
\hline & & $\begin{array}{l}\text { (4) Strengthen civilized tourism } \\
\text { education for tourists, and ensure that } \\
\text { the customs of organizing groups, } \\
\text { leaving the country, transportation, } \\
\text { landing, and travel are } \\
\text { properly handled }\end{array}$ \\
\hline & & $\begin{array}{l}\text { (5) Standardize the order of the } \\
\text { tourism market }\end{array}$ \\
\hline
\end{tabular}

\section{References}

1. Coe, C.A. 'Civilized city': How embedded civil society networks frame the debate on urban green space in Hanoi, Vietnam. Asian J. Commun. 2015, 25, 617-635. [CrossRef]

2. Daqian, S.; Ke, H.; Jia, C. Does urban civilization promote high-quality development of enterprises?-From the perspective of environmental regulation and transaction costs. Ind. Econ. Res. 2019, 103, 27-38.

3. Wu, H.; Wu, S.; Chen, H. Urban civilization, transaction cost and the "fourth profit Source" of enterprises—Evidence based on nuclear matching multiple difference method between civilized cities and private listed companies in China. Chin. Ind. Econ. 2015, 28, 114-129.

4. Liu, Z.; Liu, C. Study on the influence effect of civilized city on industrial structure upgrading-Quasi-natural experiment from civilized city selection. Ind. Econ. Res. 2021, 23, 43-55.

5. Zhou, L.A. Research on promotion tournament mode of Local officials in China. Econ. Res. 2007, 52, 36-50.

6. Steiner, L.; Frey, B.S.; Hotz, S. European Capitals of Culture and Life Satisfaction. CREMA Work. Pap. Ser. 2013, 52, 374-394. [CrossRef]

7. Miao, N. Civilized City Competition: Promotion tournament or City Booster. Stat. Manag. 2016, 7, 48-50.

8. Zheng, W.; Zhang, D. National civilized cities and enterprise performance-Micro Evidence Based on propensity matching multiple difference method. Res. Ind. Econ. 2016, 14, 37-46.

9. Chen, R.; Yang, J.; Dai, C.; Wang, Z. The Power of Honor: Can the designation of a national Civilized City motivate local companies to reduce emissions? Ind. Econ. Res. 2021, 19, 71-84.

10. Gong, F.; Li, B.; Lu, H. Analysis on the effect of civilized city on people's livelihood-Quasi-natural experimental evidence from prefecture-level cities. J. Yunnan Univ. Financ. Econ. 2018, 34, 3-17.

11. Zou, Z.; Wen, L. To create a national civilized city and regional economic growth-Testing the mediating and moderating effects of urban innovation capacity. Res. Inst. Econ. 2019, 16, 74-90.

12. Manan, A.; Muhazar, M.; Syahputra, R.; Salasiyah, C.I. Banda Aceh as a Civilized City Model. J. Ilm. Peuradeun 2020, 8, 243-258. [CrossRef]

13. Zhang, C.; Liu, Q.; Ge, G.; Hao, Y.; Hao, H. The impact of government intervention on corporate environmental performance: Evidence from China's national civilized city award. Financ. Res. Lett. 2021, 39, 101624. [CrossRef]

14. Gomes, P.; Librero-Cano, A. Evaluating three decades of the European Capital of Culture programme: A difference-in-differences approach. J. Cult. Econ. 2018, 42, 57-73. [CrossRef]

15. Tan, N.; Huang, W. Does the Policy of Cultural Industry Agglomeration drive regional tourism economy growth? —Evidence from the quasi-natural experiment of cultural and creative parks. Chin. Soft Sci. 2021, 68-75.

16. Shi, P.; Zhang, Y.; Xu, T.; Shen, J. Evaluation of the effect of establishing the whole region tourism demonstration area on regional tourism economic development-Empirical analysis based on differential difference. Macroecon. Res. 2020, 15, 122-132.

17. Li, B.; Mi, Z.; Zhang, Z. Contribution and Influence mechanism of leisure agriculture to rural economic development-A case study of national leisure agriculture and rural tourism demonstration county. Econ. Geogr. 2020, 40, 154-162.

18. Li, Y.; Peng, W.; Liang, J. Study on the influence of eco-tourism demonstration area on the green development of regional economy-Based on the perspective of quasi-natural experiment. Explor. Econ. Issues 2020, 40, 21-30. 
19. Deng, T.T.; Zou, G.; Ma, M. Has the strategy of International Tourism Island promoted the internationalization level of Hainan tourism industry?-Policy effect evaluation based on differential difference method. Econ. Manag. 2016, 38, 147-155.

20. Liu, R.; Li, L.; Kang, Y.; Yong, Z. Scenic spot selection, government public service supply and regional tourism economic development. Chin. Ind. Econ. 2018, 34, 118-136.

21. Chai, K.-C.; Xie, D.-C.; Yeh, C.-P.; Lan, H.-R.; Cui, Z.-X. Chinese national civilized city and corporate social responsibility: Will civilized city promote corporate social responsibility? Appl. Econ. Lett. 2021, 15, 1-4. [CrossRef]

22. Bao, Z. Civilized City: A new model of Sustainable urbanization with Chinese characteristics. Marx. Stud. 2011, 28, 5-16.

23. Zhu, J.; Ya, L.W.; Hou, L. How does civilized City evaluation promote labor inflow?-Quasi-natural experimental evidence from prefecture-level cities. Ind. Econ. Res. 2021, 19, 43-56.

24. Tan, J.; Ding, H.; Yan, L. Does the establishment of pilot free trade zones improve the investment efficiency of enterprises. $J$. Shanxi Univ. Financ. Econ. 2019, 41, 16-29.

25. Abadie, A. Semiparametric Difference-in-Differences Estimators. Rev. Econ. Stud. 2010, 72, 1-19. [CrossRef]

26. Zhao, J.B. Doubly Robust Difference-in-Differences Estimators. J. Econom. 2020, 219, 101-122.

27. Wen, Z.; Ye, B. Mediating effects analysis: Method and model development. Adv. Psychol. Sci. 2014, 22, 731-745. [CrossRef]

28. Yu, F.; Huang, Z.; Cao, F. The contribution of system change to China's tourism economic growth-Based on the perspective of marketization process. Travel J. 2013, 28, 13-21.

29. Liu, R.; Mao, Y.; Kang, Y. Deregulation of system, stimulation of market vitality and development of tourism economy-Evidence from China's cultural system reform. Econ. Res. 2020, 55, 115-131.

30. Li, G.; Hu, Z.; Cao, J. Institutional change and tourism economic Growth-Policy evaluation of the COMMISSION based on differential difference method. Travel J. 2018, 33, 13-24.

31. Zheng, W.; Ji, H.; Lin, C.; Wang, W.; Yu, B. Using a heuristic approach to design personalized urban tourism itineraries with hotel selection. Tour. Manag. 2020, 76, 103956. [CrossRef]

32. Liao, B.; Yu, S.; Wang, M. A model of economic loss of environmental carrying capacity caused by flood disasters in urban tourism areas. Arab. J. Geosci. 2021, 14, 913. [CrossRef]

33. Cartier, C.C. Governmentality and the urban economy: Consumption, excess, and the 'civilized city' in China. New Ment. Gov. China 2016, 13, 56-73.

34. Wang, J.; Huang, X.; Gong, Z.; Cao, K. Dynamic assessment of tourism carrying capacity and its impacts on tourism economic growth in urban tourism destinations in China. J. Destin. Mark. Manag. 2020, 15, 100383. [CrossRef]

35. Wang, J.; Li, T. A study on the evaluation of tourist destination brand identity-A case study of China's excellent tourist cities. Travel J. 2012, 27, 43-51.

36. Yin, H.; Zhu, Y. The influence of big data and informatization on tourism industry. In Proceedings of the 2017 International Conference on Behavioral, Economic, Socio-Cultural Computing (BESC), Krakow, Poland, 16-18 October 2017; pp. 1-5.

37. Yang, Y.; Ding, Z.; Ge, J.; Wu, Y.; Wang, Y. The coupling and coordination relationship between rural tourism informatization and regional tourism economy in Jiangsu Province. Econ. Geogr. 2018, 38, 220-225.

38. Grant, A. Hyperbuilding the civilized city: Ethnicity and marginalization in Eastern Tibet. Crit. Asian Stud. 2018, 50, 537-555. [CrossRef]

39. Kang, Y. Principles of Landscape Ecology in the Construction of Hydro-Ecological Civilized City. J. Landsc. Res. 2020, 12, 90-93. [CrossRef]

40. $\mathrm{Hu}, \mathrm{Z}$; Rong, X.; Xiong, X. Study on the coordination degree of tourism development and ecological civilization construction in National Tourism Cities. Acad. Forum 2016, 39, 51-58.

41. Zhang, T.; Wang, Z. Research on the signal mechanism of honorary titles affecting official promotion-Evidence from the national evaluation of civilized cities. China Adm. 2020, 26, 121-127.

42. Qiao, J.; Huang, Z. The impact of civilized city selection on urban economic growth: Promotion or inhibition-Quasi natural experiment from the selection of civilized cities. Mod. Financ. Econ. J. Tianjin Univ. Financ. Econ. 2020, 40, 98-113.

43. Ming, L.; Huang, Y.; Zhu, H.; Zhao, Q.L. Is the national civilized city selection "welfare" or "trap"—From the perspective of urban tourism development. Investig. Res. 2021, 40, 54-70. 